\title{
Breast-feeding in a UK urban context: who breast-feeds, for how long and does it matter?
}

\author{
Charlotte M Wright ${ }^{1, *}$, Kathryn Parkinson ${ }^{2}$ and Jane Scott ${ }^{3}$ \\ 'Department of Child Health, Glasgow University, PEACH Unit, QMH Tower, Yorkhill Hospitals, Glasgow G3 8SJ, \\ UK: ${ }^{2}$ Department of Child Health, Newcastle University, Newcastle upon Tyne, UK: ${ }^{3}$ Department of Human Nutrition, \\ Glasgow University, Glasgow, UK
}

Submitted 24 February 2005: Accepted 26 0ctober 2005

\begin{abstract}
Objective: To investigate what factors relate most strongly to breast-feeding duration in order to successfully support breast-feeding mothers.

Design: Prospective birth cohort study using questionnaires, routinely collected weights and health check at age 13 months.

Setting: Gateshead, UK.

Subjects: Parents of 923 term infants born in a defined geographical area and recruited shortly after birth, $50 \%$ of whom were breast-feeding initially.

Results: Only 225 (24\%) infants were still breast-fed at 6 weeks, although 136 (15\%) continued beyond 4 months. Infants in the most affluent quintile were three times more likely to be initially breast-fed $(P<0.001)$ and five times more likely to still be feeding at 4 months $(P=0.001)$ compared with infants in the most deprived quintile. A third of breast-fed infants were given supplementary feeds in the maternity unit and this was associated with a 10-fold increase in odds of giving up breast-feeding by discharge $(P=0.001)$. Frequent feeding was reported as a reason for giving up in $70 \%$ of mothers at 6 weeks and $55 \%$ at 4 months. Those infants who stopped breastfeeding earliest showed the most rapid weight gain and were tallest at age 13 months. Non-breast-fed infants had 50\% more family doctor contacts up to age 4 months $(P=0.005)$.

Conclusions: Initiation of breast-feeding in urban Britain remains strongly determined by socio-economic background and early cessation seems to be related to frequent feeding and rapid growth as well as a continuing failure to eradicate health practices that undermine breast-feeding. Those infants not receiving breast milk suffered increased morbidity, but the apparent association between breast-feeding duration and growth probably reflects reverse causation.
\end{abstract}

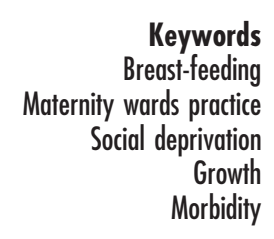

Breast-feeding is of vital importance in public health terms. Worldwide, the use of infant formula is one of the most important causes of preventable mortality in infancy ${ }^{1-3}$, while in developed countries it is associated with increased morbidity ${ }^{4,5}$ and mortality ${ }^{6}$ in infancy and even, possibly, reduced later intelligence quotient ${ }^{7}$ and increased risk of adult ill health ${ }^{8}$. However, re-establishing breast-feeding within what has become a strong bottlefeeding culture is not easy, and in Britain cessation rates before 6 weeks remain high ${ }^{9}$. Initiation rates for breastfeeding have risen in recent years in Britain but strong social class differences remain, which means that mothers electing to breast-feed in poor urban areas risk being isolated and unsupported in what has become an unfamiliar practice po,11. $^{10}$.

Early difficulties with breast-feeding may relate to problems of positioning and perceived milk supply ${ }^{9,12}$. Studies have shown that breast-fed infants feed more frequently ${ }^{13}$, sleep though the night later ${ }^{14}$, and appear to gain weight more slowly than formula-fed infants later in the first year ${ }^{15}$, but we do not know if these factors influence mothers in their decision to continue or stop breast-feeding. In order to successfully support breastfeeding mothers, a better understanding is needed of what factors relate most strongly to breast-feeding duration.

As part of a large-scale prospective study of feeding and growth in infancy, we were able to survey mothers about their decision to stop breast-feeding and relate breastfeeding duration to sociodemographic factors as well as growth and morbidity in infancy.

\section{Method}

The Gateshead Millennium Baby Study recruited subjects between June 1999 and May 2000. All babies born to Gateshead-resident mothers in 34 pre-specified recruiting 
weeks were eligible for inclusion; however, for the present analysis, infants born before 37 weeks' gestation were excluded as well as the few (4\%) infants from minority groups, who tended to have very different feeding and growth patterns. Twins were not excluded, with the analysis conducted per infant rather than per mother. Mothers were recruited on the maternity unit or shortly after discharge, when basic demographic and background information was collected. Thereafter, parents were surveyed at 6 weeks, 4 and 8 and 12 months by postal questionnaire, which asked whether any breast-feeds were still being given and whether the child had seen their family doctor, suffered a cold, diarrhoea, rash or chest infection, or been admitted to hospital. At 6 weeks and 4 months a set of questions was included for mothers who had commenced but given up breast-feeding. These asked exactly when she had stopped, whether she would have liked to have fed for longer and offered six possible reasons why she might have given up, answered using a 5point Likert scale (strongly agree, agree, uncertain, disagree, strongly disagree) as well as a free text option.

In addition to the main questionnaires, all mothers were given a breast-feeding audit form commissioned by the Gateshead maternity unit, which was completed after discharge, specifically asking about their experience of feeding their baby in the maternity unit.

Socio-economic information collected at recruitment was used to dichotomise families into affluent (homeowner, car owner and one or more employed parent) and deprived (one or more of rented housing, no car and no employed parent); in addition, their Townsend deprivation score quintile was identified from their post code ${ }^{16}$.

All children in the UK are routinely weighed in community-based well-baby clinics by public health nurses and these weights are recorded in parent-held child health records, as are the results of child surveillance examinations. Parents transcribed these weights onto each questionnaire. At the age of 13 months, families were invited to a health check where the baby's weight and length were measured by a research nurse. The attending parent(s) were also measured and the height of absent parents obtained by report.

\section{Analysis}

All measurements were converted into standard deviation (SD) scores compared with the UK 1990 growth reference ${ }^{17,18}$. The cleaning and summarisation of the weight data have been described previously ${ }^{19}$. For each child, all available weights within four age ranges (1-2, 3-6, 7-9 and 10-18 months) were identified and the average SD score per child for that time period calculated. These supplied SD scores at around the ages of 6 weeks, 4 , 8 and 12 months. Weight gain was then assessed using the Thrive Index, a measure of conditional weight gain which uses the method of residuals to adjust for regression to the mean, the tendency for very small or large infants to shift towards the average over time $e^{20}$. Lengths were adjusted for average parental height and body mass index (BMI) adjusted for maternal BMI using a similar approach.

We examined univariate associations using the chisquare test for categorical outcomes and analysis of variance for trend for continuous outcomes. We examined the relative influence of different potentially confounding risk factors by placing all relevant factors into the same logistic regression model as predictors.

\section{Results}

There were 923 term infants (of 912 mothers) in total, of whom 449 (49\%) initiated breast-feeding. Only 225 (24\%) of these were still receiving any breast milk at 6 weeks, although 136 (15\%) were breast-fed for more than 4 months. Infants in the most affluent Townsend score quintile were three times more likely to be initially breast-fed $(P<0.001)$, and five times more likely to still be feeding at 4 months, than infants in the most deprived quintile $(P=0.001)$, even after adjustment for maternal educational qualifications and household amenities (Table 1).

The maternity unit breast-feeding audit, returned for 334 (74\%) infants breast-fed at birth, revealed that 163 (49\%) babies were first put to the breast within 30 minutes of birth, but that 135 (40\%) waited more than an hour. Of the 180 breast-feeding their first baby, 166 (92\%) reported receiving advice and help with their first feed, as did 84 $(50 \%)$ of the remainder. At least one supplementary milk feed was given on the maternity unit by bottle or cup to 110 (33\%) infants and some difficulties feeding were reported for 193 (58\%) infants. Both difficulties feeding and supplementary feeds strongly predicted a baby being described as solely bottle-fed by the time they went home, but supplementary feeds remained a strong risk factor independent of feeding difficulties. This association was unaffected by adjustment for deprivation (Table 2).

The section on stopping breast-feeding was completed for 141 (63\%) infants who stopped breast-feeding before 6 weeks and 67 (75\%) of those stopping between 6 weeks and 4 months. The majority of mothers would have preferred to feed for longer; the commonest explanation endorsed by mothers was that their baby was hungry and in free text a number (10\% at 6 weeks, $12 \%$ at 4 months) also spontaneously mentioned that their baby fed too frequently. One or both of these reasons was cited in twothirds at 6 weeks and half at 4 months. In the first 6 weeks problems with cracked or sore nipples were also fairly commonly cited (Table 3).

Examination of the growth data by feeding group revealed that the formula-fed infants were the lightest at birth but that at every other time point the infants breastfed for more than 4 months were lightest, while those breast-fed for less than 6 weeks were the heaviest and had gained weight the fastest. At the age of 12 months those infants breast-fed the longest were also the shortest, 
Table 1 Initiation and continuance of breast-feeding by level of deprivation

\begin{tabular}{|c|c|c|c|c|c|c|}
\hline & \multicolumn{2}{|c|}{ Breast-fed at birth $(N=449)$} & \multicolumn{2}{|c|}{$\begin{array}{l}\text { Ceased breast-feeding } \\
\text { by } 6 \text { weeks }(N=224)\end{array}$} & \multicolumn{2}{|c|}{$\begin{array}{l}\text { Still breast-feeding at } \\
4 \text { months }(N=136)\end{array}$} \\
\hline & $\%(n)$ & OR $(95 \% \mathrm{Cl})^{*}$ & $\%(n)$ & OR $(95 \% \mathrm{Cl})^{*}$ & $\%(n)$ & OR $(95 \% \mathrm{Cl})^{*}$ \\
\hline Deprived & $33.2(146)$ & 1.00 & $66.7(98)$ & 1.00 & $9.5(27)$ & 1.00 \\
\hline Affluent & $65.3(295)$ & $2.08(1.5-2.9)$ & $41.7(126)$ & $0.64(0.39-1.05)$ & $26.4(106)$ & $1.20(0.67-2.14)$ \\
\hline \multicolumn{7}{|l|}{ Maternal education } \\
\hline Higher education & $84.2(128)$ & $8.14(4.6-14.5)$ & $25.8(34)$ & $0.31(0.15-0.68)$ & $48.9(68)$ & $7.69(3.2-18.4)$ \\
\hline Beyond 16 years & $45.8(49)$ & $1.73(1.0-2.9)$ & $62.0(31)$ & $1.29(0.54-3.07)$ & $10.9(9)$ & $1.22(0.4-3.4)$ \\
\hline GCSE & $49.7(213)$ & $2.03(1.4-3.0)$ & $57.9(125)$ & $1.07(0.54-2.13)$ & $13.9(48)$ & $1.65(0.7-3.7)$ \\
\hline None or other & $25.0(51)$ & 1.00 & $66.7(34)$ & 1.00 & $6.8(8)$ & 1.00 \\
\hline \multicolumn{7}{|c|}{ Townsend deprivation score quintile } \\
\hline 1 (most affluent) & $74.5(108)$ & $2.78(1.6-4.9)$ & $28.8(34)$ & $0.30(0.13-0.69)$ & $38.8(52)$ & $3.11(1.3-7.3)$ \\
\hline 2 & $61.3(114)$ & $1.73(1.0-2.9)$ & $48.3(56)$ & $0.70(0.32-1.55)$ & $23.8(35)$ & $1.57(0.7-3.7)$ \\
\hline 3 & $45.6(93)$ & $1.47(0.9-2.3)$ & $53.1(51)$ & $0.55(0.25-1.19)$ & $15.4(24)$ & $1.44(0.6-3.3)$ \\
\hline 4 & $42.3(77)$ & $1.52(1.0-2.4)$ & $64.9(50)$ & $0.80(0.36-1.80)$ & $9.3(12)$ & $0.87(0.4-2.2)$ \\
\hline 5 (most deprived) & $26.6(45)$ & 1.00 & $73.3(33)$ & 1.00 & $7.8(9)$ & 1.00 \\
\hline
\end{tabular}

OR - odds ratio; $\mathrm{Cl}$ - confidence interval.

${ }^{*}$ Logistic regression including all three variables in model as predictors.

Table 2 Likelihood of still breast-feeding after discharge related to difficulties feeding and any supplementary feed given on the maternity unit

\begin{tabular}{|c|c|c|c|c|}
\hline \multicolumn{2}{|c|}{$\begin{array}{l}\text { Number (\%) with } \\
\text { or without } \\
\text { difficulties feeding }\end{array}$} & \multicolumn{2}{|c|}{$\begin{array}{c}\text { Number (\%) } \\
\text { given supplement } \\
\text { feed }\end{array}$} & \multirow{2}{*}{$\begin{array}{c}\begin{array}{c}\text { Number }(\%) \text { in each category } \\
\text { who had given up } \\
\text { breast-feeding by discharge }\end{array} \\
46(55)\end{array}$} \\
\hline Yes & $185(57)$ & Yes & $84(45)$ & \\
\hline & & No & $101(55)$ & $12(12)$ \\
\hline \multirow[t]{2}{*}{ No } & $140(43)$ & Yes & $33(24)$ & $10(30)$ \\
\hline & & No & 107 (76) & $0(0)$ \\
\hline
\end{tabular}

Odds ratio $(95 \% \mathrm{Cl})$ of giving up breast-feeding once home, from logistic regression model containing both variables as predictors: supplement, 12.96 (6.42-26.18), $P<0.001$; difficulties feeding, 4.55 (2.10-9.88), $P<0.001$.

Table 3 Reasons why mothers gave up breast-feeding before 4 months

\begin{tabular}{|c|c|c|c|}
\hline & \multicolumn{2}{|c|}{ When mothers gave up } & \multirow[b]{2}{*}{$P\left(\chi^{2}\right.$ test $)$} \\
\hline & $<6$ weeks & 6 weeks to 4 months & \\
\hline \multicolumn{4}{|c|}{ I would have liked to continue breast-feeding for longer } \\
\hline Yes & $60(90)$ & $61(41)$ & NS \\
\hline Maybe & $24(35)$ & $24(16)$ & \\
\hline No & $16(24)$ & $15(10)$ & \\
\hline \multicolumn{4}{|l|}{ I stopped breast-feeding because } \\
\hline My baby seemed hungry/frequent feeding & $71(94)$ & $55(36)$ & 0.04 \\
\hline I had cracked/sore nipples, mastitis etc. & $42(59)$ & $3(2)$ & $<0.001$ \\
\hline I wasn't producing enough milk & $31(43)$ & $28(18)$ & NS \\
\hline My baby was not gaining weight & $13(18)$ & $11(7)$ & NS \\
\hline I thought it was the right time & $27(36)$ & $35(21)$ & NS \\
\hline My family and friends told me to & $8(11)$ & $3(2)$ & NS \\
\hline
\end{tabular}

NS - not significant.

Values are \% $(n)$ agreeing or strongly agreeing with the statement (mothers could agree with as many statements as they wished).

significantly so after adjustment for parental height. There was no difference in BMI, even after adjusting for maternal BMI (Table 4). When ever breast-fed infants were compared with never breast-fed infants there were no differences, except in birth weight (mean difference 0.18 SD score, $P=0.012$ ( $t$-test $)$.
Children in the cohort saw their family doctor a mean of 2.7 (SD 1.8) times in the first year, excluding immunisations and surveillance contacts. In the first 4 months nonbreast-fed babies were $45 \%$ more likely to be taken to the doctor, with a smaller non-significant excess between 4 and 12 months. Adjustment for Townsend score 
Table 4 Growth of subjects by duration of breast-feeding

\begin{tabular}{|c|c|c|c|c|c|c|c|}
\hline $\begin{array}{l}\text { Breast-feeding } \\
\text { duration }\end{array}$ & $\begin{array}{c}\text { Birth } \\
\text { weight }\end{array}$ & $\begin{array}{l}\text { Weight } \\
\text { at } 1 \text { year }\end{array}$ & $\begin{array}{l}\text { Conditional } \\
\text { weight gain } \\
\text { birth to } \\
12 \text { months }\end{array}$ & Length & $\begin{array}{l}\text { Length adjusted } \\
\text { for parental } \\
\text { height }\end{array}$ & BMI & $\begin{array}{c}\text { BMI adjusted } \\
\text { for maternal } \\
\text { BMI }\end{array}$ \\
\hline More than 4 months & $0.00(1.1)$ & $0.05(1.1)$ & $0.05(1.0)$ & $0.48(1.0)$ & $0.37(0.9)$ & $-0.36(1.1)$ & $-0.46(1.1)$ \\
\hline 6 weeks to 4 months & $-0.13(1.0)$ & $0.21(1.0)$ & $0.24(0.9)$ & $0.65(1.0)$ & $0.55(0.9)$ & $-0.34(1.0)$ & $-0.43(1.0)$ \\
\hline Less than 6 weeks & $-0.15(1.0)$ & $0.27(1.1)$ & $0.30(1.0)$ & $0.65(1.1)$ & $0.67(1.0)$ & $-0.24(1.0)$ & $-0.35(1.0)$ \\
\hline Total ever breast-fed & $-0.10(1.1)$ & $0.18(1.0)$ & $0.20(1.0)$ & $0.59(1.0)$ & $0.55(1.0)$ & $-0.30(1.0)$ & $-0.40(1.0)$ \\
\hline Formula-fed only & $-0.28(1.0)$ & $0.11(1.0)$ & $0.20(0.9)$ & $0.50(1.0)$ & $0.62(0.9)$ & $-0.30(1.0)$ & $-0.41(1.0)$ \\
\hline $\begin{array}{l}\text { Number with } \\
\text { measurements }\end{array}$ & 898 & 755 & 755 & 740 & 686 & 740 & 706 \\
\hline$P^{\star}$ & 0.006 & NS & NS & NS & 0.02 & NS & NS \\
\hline
\end{tabular}

BMI - body mass index; NS - not significant.

All values are mean (standard deviation) standard deviation scores.

${ }^{*}$ Analysis of variance for trend with four feeding categories as predictors.

deprivation quintile and educational level only slightly diminished this association (Table 5).

\section{Discussion}

\section{Strengths and limitations}

This was a fairly large study but with relatively few breastfeeders, particularly after the first few weeks. It was thus better placed to consider the factors that lead women to start or stop breast-feeding than to consider its health effects. A particular strength was that the data were collected contemporaneously and did not rely on longterm recall. The study was entirely observational, but had a wide range of other information about the infants and their families, so that it was possible to adjust for important confounders.

\section{Influences on initiation and continuance of breast- feeding}

The most important influences, as ever, were social and educational factors. These had such a potent influence that both deprivation score and maternal education remained independently predictive of both initiation and continuance of breast-feeding, while for initiation the effect was so strong that both the markers of deprivation were independently predictive as well. Thus infants who are already materially and educationally disadvantaged also tend to lack the protective benefit of breast-feeding, a vivid example of the concept of cumulative disadvantage. None of these sociodemographic factors is itself open to change by a direct breast-feeding intervention, but these findings further illustrate the need to develop interventions suitable for mothers living in deprivation and target most effort towards poorer communities.

However, not all influences were purely social. This study also supplies further evidence of the potential importance of the maternity hospital experience in establishing breast-feeding. There was a high level of commitment to breast-feeding by midwifery staff, who did their best to offer help and support mothers, but $40 \%$ of mothers still waited more than an hour before first putting their baby to the breast and a third of infants were given supplementary feeds. Supplementation was strongly related to reported difficulties with breast-feeding, which strongly predicted early cessation, but even where there were no reported difficulties supplementation itself was strongly related to cessation. We cannot fully tease out the extent to which supplementation might simply represent a decision by the mother to cease breast-feeding, but it is hard to explain why this might happen in the absence of reported feeding difficulties. Early supplementation with infant formula has previously been negatively associated with breast-feeding duration ${ }^{21}$ and is a hospital practice open to change that is targeted by the UNICEF Baby-friendly Hospital Initiative.

Table 5 Relative risk of contact with the family doctor by mode of feeding

\begin{tabular}{lccccc}
\hline Time interval & $\begin{array}{c}\text { Number receiving breast } \\
\text { milk throughout period }\end{array}$ & $\begin{array}{c}\text { Number bottle-fed for } \\
\text { some or all of period }\end{array}$ & $\begin{array}{c}\text { Relative risk of } \\
\text { seeing doctor }\end{array}$ & $P\left(\chi^{2}\right.$ test $)$ & OR (95\% Cl)† \\
\hline Birth to 6 weeks & 217 & 523 & 1.45 & 0.004 & $1.73(1.19-2.51)$ \\
6 weeks to 4 months & 132 & 545 & 1.45 & 0.011 & $1.72(1.13-2.60)$ \\
4 to 8 months & 35 & 511 & 1.32 & 0.10 & $1.79(0.89-3.58)$ \\
8 to 12 months & 32 & 417 & 1.25 & 0.18 & $1.64(0.79-3.40)$ \\
\hline
\end{tabular}

OR - odds ratio; $\mathrm{Cl}$ - confidence interval.

${ }^{*}$ For those bottle-fed for some or all of that time period, compared with rest of cohort.

† Logistic regression, adjusted for Townsend deprivation quintile and maternal educational qualifications. 
Two-thirds of mothers giving up before 6 weeks perceived this as at least partly because their infant was hungry or fed too frequently. This is not a factor that has been specifically asked about in previous studies, although similar reasons were given by Scottish women for introducing solids before 12 weeks $^{22}$. We know from other data on this cohort that the breast-feeding infants fed more frequently than bottle-fed infants in the early days ${ }^{13}$. These findings suggest, as others have argued ${ }^{10,11}$, that there is a need to properly prepare mothers for the time commitment of breast-feeding. They also raise the question of whether it is realistic to expect mothers to maintain exclusive as opposed to partial breast-feeding up to 6 months, if this is already such an important factor before the age of 4 months.

\section{Impact of breast-and bottle-feeding on bealth}

These data again illustrate the protective effect of breast milk against early morbidity, even in a developed country. Similar findings have recently been reported from Australia $^{5}$, while a recent US study found an association between artificial feeding and neonatal mortality ${ }^{6}$. All these studies are observational and therefore cannot reliably infer causation, but the Belarus trial of breastfeeding promotion also found significantly lower rates of gastrointestinal infections and a trend to fewer deaths ${ }^{23}$.

Different growth patterns have been described in breast-fed infants in previous papers ${ }^{15,24}$, with exclusively breast-fed infants tending to grow faster in the early weeks and slower thereafter, leading to the suggestion that formula milk may in some way lead to excess weight gain and thus predispose to obesity and adult ill health ${ }^{25}$. However, evidence from the Belarus trial provides persuasive evidence that the explanation for this is in fact reverse causation ${ }^{26}$ and our data lend further support for this. Between our feeding groups, the infants breastfed for the shortest time, rather than the formula-fed group, showed the most rapid early weight gain and were tallest at one year, while those breast-fed the longest were the shortest. This suggests that the higher nutrient requirements of the genetically taller infants led them to make more demands on their mother and make her more likely to give up. This is supported by other work in this cohort which found that frequent feeding in the early days was associated with more rapid weight gain ${ }^{13}$ and with earlier complementary feeding ${ }^{20}$.

In conclusion, initiation of breast-feeding in urban Britain remains strongly determined by socio-economic background, but the factors that lead to early cessation seem to reflect more general difficulties with the understanding and prioritisation of breast-feeding as an activity and a continuing failure to eradicate health practices that undermine it. Those infants not receiving breast milk suffer increased morbidity, but the apparent association between breast-feeding duration and growth probably reflects reverse causation.

\section{Acknowledgements}

The study would not have been possible without the invaluable support of the midwives at the Gateshead and Newcastle maternity units and the loyal participation of all the parents. Our thanks to Jayne Kelly, Anne Trail, Alison Smith, Jane Jarvis and Ann Pattison for their work on the study and to Philip Lowe for computing support. The research was funded by the Henry Smith Charity and Sport Aiding Research in Kids (SPARKS).

\section{References}

1 WHO. Effect of breastfeeding on infant and child mortality due to infectious diseases in less developed countries: a pooled analysis. WHO Collaborative Study Team on the Role of Breastfeeding on the Prevention of Infant Mortality. Lancet 2000; 355: 451-5.

2 Betran AP, de Onis M, Lauer JA, Villar J. Ecological study of effect of breastfeeding on infant mortality in Latin America. British Medical Journal 2001; 323: 303-6.

3 Huffman SL, Zehner ER, Victora C. Can improvements in breastfeeding practices reduce neonatal mortality in developing countries? Midwifery 2001; 17: 80-92.

4 Kramer MS, Kakuma R. Optimal duration of exclusive breastfeeding. Cochrane Database of Systematic Reviews 2002; (1): CD003517.

5 Oddy WH, Sly PD, de Klerk NH, Landau LI, Kendall GE, Holt PG, et al. Breastfeeding and respiratory morbidity in infancy: a birth cohort study. Archives of Disease in Childhood 2003; 88: $224-8$.

6 Chen A, Rogan WJ. Breastfeeding and the risk of postneonatal death in the United States. Pediatrics 2004; 113: e435-9.

7 Lucas A, Morley R, Cole T, Lister G, Leeson-Payne C. Breast milk and subsequent intelligence quotient in children born preterm. Lancet 1992; 339: 261-4.

8 Singhal A, Cole TJ, Lucas A. Early nutrition in preterm infants and later blood pressure: two cohorts after randomised trials. Lancet 2001; 357: 413-9.

9 Hamlyn B, Brooker S, Oleinikova K, Wands S. Infant Feeding 2000. London: Department of Health, 2003.

10 Hoddinott P, Pill R. Qualitative study of decisions about infant feeding among women in east end of London. British Medical Journal 1999; 318: 30-4.

11 Scott JA, Mostyn T. Women's experiences of breastfeeding in a bottle-feeding culture. Journal of Human Lactation 2003; 19: $270-7$.

12 Cooke M, Sheehan A, Schmied V. A description of the relationship between breastfeeding experiences, breastfeeding satisfaction, and weaning in the first 3 months after birth. Journal of Human Lactation 2003; 19: $145-56$.

13 Casiday RE, Wright CM, Panter-Brick C, Parkinson KN. Do early infant feeding patterns relate to breastfeeding continuation and weight gain? Data from a longitudinal cohort study. European Journal of Clinical Nutrition 2004; 58: $1290-6$.

14 Wright P. Development of feeding behaviour in early infancy: implications for obesity. Health Bulletin 1981; 39: $197-205$.

15 Dewey KG, Peerson JM, Brown KH, Krebs NF, Michaelsen KF, Persson LA, et al. Growth of breastfed infants deviates from current reference data: a pooled analysis of US, Canadian, and European data sets. World 
Health Organization Working Group on Infant Growth. Pediatrics 1995; 96: 495-503.

16 Townsend P, Phillimore P, Beattie A. Health and Deprivation: Inequality and the North. London: Croom Helm, 1988.

17 Freeman JV, Cole TJ, Chinn S, Jones PRM, White EM, Preece MA. Cross sectional stature and weight reference curves for the UK, 1990. Archives of Disease in Childhood 1995; 73: 17-24.

18 Preece M, Freeman J, Cole T. Sex differences in weight in infancy. Published centile charts have been updated. British Medical Journal 1996; 313: 1486

19 Wright CM, Parkinson KN, Drewett RF. Why are babies weaned early? Data from a prospective population based cohort study. Archives of Disease in Childhood 2004; 89: 813-6.

20 Wright CM, Waterston A, Matthews JNS, Aynsley-Green A. What is the normal rate of weight gain in infancy? Acta Paediatrica 1994; 83: 351-6.

21 Ekstrom A, Widstrom AM, Nissen E. Duration of breastfeed- ing in Swedish primiparous and multiparous women. Journal of Human Lactation 2003; 19: 172-8.

22 Alder EM, Williams FL, Anderson AS, Forsyth S, Florey CduV, van der Velde P. What influences the timing of the introduction of solid food to infants? British Journal of Nutrition 2004; 92: 527-31.

23 Kramer MS, Chalmers B, Hodnett ED, Sevkovskaya Z, Dzikovich I, Shapiro S, et al. Promotion of Breastfeeding Intervention Trial (PROBIT): a randomized trial in the Republic of Belarus. Journal of the American Medical Association 2001; 285: 413-20.

24 Cole TJ, Paul AA, Whitehead RG. Weight reference charts for British long-term breastfed infants. Acta Paediatrica 2002; 91: $1296-300$.

25 Singhal A, Lucas A. Early origins of cardiovascular disease: is there a unifying hypothesis? Lancet 2004; 363 : 1642-5.

26 Kramer MS, Guo T, Platt RW, Shapiro S, Collet JP, Chalmers B, et al. Breastfeeding and infant growth: biology or bias? Pediatrics 2002; 110: 343-7. 